CHRONIC OBSTRUCTIVE PULMONARY DISEASE

\title{
Effects of cyclo-oxygenase inhibition on exhaled eicosanoids in patients with COPD
}

\author{
P Montuschi, F Macagno, P Parente, S Valente, L Lauriola, G Ciappi, S A Kharitonov, P J Barnes, \\ G Ciabattoni
}

Thorax 2005;60:827-833. doi: 10.1136/thx.2004.035592

\begin{abstract}
See end of article for authors' affiliations

Correspondence to: Professor P Montuschi, Department of Pharmacology, Faculty of Medicine, Catholic University of the Sacred Heart, Largo F Vito 1 , 00168 Rome, Italy; pmontuschi@rm.unicatt.it
\end{abstract}

Received 11 October 2004 Accepted 12 May 2005

\begin{abstract}
Background: Leukotriene (LT) $B_{4}$ concentrations are increased and prostaglandin (PG) $E_{2}$ concentrations are decreased in exhaled breath condensate $(E B C)$ in patients with chronic obstructive pulmonary disease (COPD). A study was undertaken to investigate the short term effects of cyclo-oxygenase (COX) inhibition on exhaled $\mathrm{LTB}_{4}$ and $\mathrm{PGE}_{2}$ concentrations in patients with COPD and to identify the COX isoform responsible for exhaled $\mathrm{PGE}_{2}$ production.

Methods: Two studies were performed. A double blind, crossover, randomised, placebo controlled study with ibuprofen (400 mg qid for 2 days), a non-selective COX inhibitor, was undertaken in 14 patients with stable COPD, and an open label study with oral rofecoxib ( $25 \mathrm{mg}$ once a day for 5 days), a selective COX-2 inhibitor, was undertaken in a different group of 16 COPD patients. EBC was collected before and after drug treatment. Exhaled $\mathrm{LTB}_{4}$ and $\mathrm{PGE}_{2}$ concentrations were measured with specific immunoassays. Results: All patients complied with treatment as indicated by a reduction in ex vivo serum thromboxane $B_{2}$ concentrations (ibuprofen) and a reduction in lipopolysaccharide induced increase in ex vivo plasma $\mathrm{PGE}_{2}$ values (rofecoxib) of more than $80 \%$. Exhaled $\mathrm{LTB}_{4}$ was increased after ibuprofen (median 175.5 (interquartile range 128.8-231.5) pg/ml $v 84.0(70.0-98.5) \mathrm{pg} / \mathrm{ml}, \mathrm{p}<0.001$ ) and exhaled $\mathrm{PGE}_{2}$ was reduced (93.5 (84.0-105-5) pg/ml v $22.0(15.0-25.5) \mathrm{pg} / \mathrm{ml}, \mathrm{p}<0.0001)$. Rofecoxib had no effect on exhaled $\mathrm{LTB}_{4}(\mathrm{p}=0.53)$ or $\mathrm{PGE}_{2}(\mathrm{p}=0.23)$.

Conclusions: Non-selective COX inhibition decreases $\mathrm{PGE}_{2}$ and increases $\mathrm{LTB}_{4}$ in $\mathrm{EBC}$, whereas selective COX-2 inhibition has no effect on these eicosanoids. $\mathrm{PGE}_{2}$ in $E B C$ is primarily derived from COX-1 activity, and COX inhibition may redirect arachidonic acid metabolism towards the 5 -lipoxygenase pathway.
\end{abstract}

\footnotetext{
$\mathrm{C}$
} oncentrations of leukotriene (LT) $\mathrm{B}_{4}$, a potent neutrophil chemoattractant, are detectable in sputum in patients with stable chronic bronchitis ${ }^{1}$ and are raised in patients with chronic obstructive pulmonary disease (COPD) during acute exacerbations. ${ }^{2}$ Prostaglandin (PG) $\mathrm{E}_{2}$, an endogenous bronchodilating compound, may have antiinflammatory effects in the airways. ${ }^{3-5}$ The isoprostanes are prostaglandin-like compounds which are formed by the free radical catalysed peroxidation of arachidonic acid in the plasma membrane phospholipids. ${ }^{67}$

$\mathrm{LTB}_{4}, \mathrm{PGE}_{2}$, and 8-isoprostane ( $15-\mathrm{F}_{2 \mathrm{t}}$-isoprostane or 8-iso$\mathrm{PGF}_{2 \alpha}$ ) concentrations are increased in exhaled breath condensate (EBC) in patients with $\mathrm{COPD}^{8}{ }^{9} \mathrm{EBC}$ is a completely non-invasive method of sampling secretions from the airways. ${ }^{10-12}$ Preliminary data show that ibuprofen, a nonselective cyclo-oxygenase (COX) inhibitor, decreases exhaled $\mathrm{PGE}_{2}$ concentrations in patients with stable COPD. ${ }^{13} \mathrm{As}^{\mathrm{PGE}_{2}}$ may have anti-inflammatory effects in the airways, raised $\mathrm{PGE}_{2}$ levels in COPD might represent a mechanism for counteracting lung inflammation in this disease. ${ }^{8}$ This is further supported by the selective increase in exhaled $\mathrm{PGE}_{2}$ in patients with COPD but not in asthmatics, ${ }^{14}$ and the correlation between exhaled $\mathrm{LTB}_{4}$ and $\mathrm{PGE}_{2}$ concentrations in patients with COPD. ${ }^{8}$ Taken together, these data indicate that non-selective COX inhibition might have important implications for lung inflammation in COPD patients.

A study was undertaken to investigate the short term effect of non-selective and selective COX-2 inhibition on exhaled $\mathrm{LTB}_{4}, \mathrm{PGE}_{2}$, and 8-isoprostane concentrations in patients with stable COPD and to identify the COX isoform responsible for exhaled $\mathrm{PGE}_{2}$ production.

\section{METHODS}

\section{Study design}

Two studies were performed. The first study was a double blind, crossover, randomised, placebo controlled study with ibuprofen. The study duration was 11 days. Patients attended the outpatient clinic at the Royal Brompton Hospital, London on days $1,3,9$, and 11 . Visit 1 was a screening visit for clinical examination, spirometric tests, skin prick testing, EBC collection, and venous blood sampling. On the same day they were randomised to receive either oral ibuprofen (400 mg every 6 hours) or matched placebo for 2 days. After 2 days of treatment and a morning dose of $400 \mathrm{mg}$ of either ibuprofen or placebo, all the above tests except skin prick tests were repeated (visit 2). After a 5 day washout the patients underwent the other arm of the study.

The second study was an open labelled, uncontrolled study of rofecoxib, a selective COX-2 inhibitor. Patients attended the COPD outpatient clinic of the Department of Internal Medicine, Catholic University of the Sacred Heart, Rome, Italy on three occasions for clinical examination, EBC collection, spirometric tests, sputum induction, measurement of arterial blood gas tensions, and venous blood sampling. After a screening visit (visit 1 ) and a 2 week run-in period (visit 2), patients were given oral rofecoxib (25 mg once daily

\footnotetext{
Abbreviations: COPD, chronic obstructive pulmonary disease; COX, cyclo-oxygenase; EBC, exhaled breath condensate; $\mathrm{FEV}_{1}$, forced expiratory volume in 1 second; FVC, forced vital capacity; $\mathrm{LTB}_{4}$, leukotriene $B_{4} ;$ NSAID, non-steroidal anti-inflammatory drug; PGE $_{2}$, prostaglandin $E_{2} ; T \times B_{2}$, thromboxane $B_{2}$
} 
USA); ${ }^{16} \mathrm{PGE}_{2}$ and 8-isoprostane were measured by radioimmunoassays using specific antisera. ${ }^{17}$ Specificity for $\mathrm{LTB}_{4}$, 8 -isoprostane, and $\mathrm{PGE}_{2}$ was previously confirmed by reverse phase-high performance liquid chromatography (RPHPLC). ${ }^{16}{ }^{17}$ The immunoassay detection limit was $4 \mathrm{pg} / \mathrm{ml}$ for $\mathrm{LTB}_{4}$ and $10 \mathrm{pg} / \mathrm{ml}$ for 8-isoprostane and $\mathrm{PGE}_{2}$. The intraassay and interassay coefficients of variation for eicosanoid were as follows: $\mathrm{LTB}_{4},<10 \%$ and $<15 \%$, respectively; 8 isoprostane, $<4 \%$ and $<11 \%$, respectively; $\mathrm{PGE}_{2},<4 \%$ and $<5 \%$, respectively.

\section{Sputum induction}

Sputum induction was performed as previously described. ${ }^{18}$ Subjects inhaled 3.5\% saline for 15 minutes via an ultrasonic nebuliser (DeVilbiss 2000, DeVilbiss Co, Heston, Middlesex, UK) with a calibrated mass median aerodynamic diameter of $4.5 \mu \mathrm{m}$ and output of $4.5 \mathrm{ml} / \mathrm{min}$. Secretions collected during the first 5 minutes were discarded to minimise squamous epithelial cell contamination. Samples were considered adequate for analysis if there was $<50 \%$ squamous cell contamination. Sputum samples were processed immediately. Dithiothreitol solution (0.1\%) (Sigma-Aldrich Co, St Louis, MO, USA) was added to the sputum and the mixture was allowed to stand for 30 minutes. Cell viability was determined by exclusion of Trypan Blue. After centrifugation at $1500 \mathrm{~g}$ for 8 minutes, the cell pellet was resuspended in $10 \mathrm{ml}$ Presercyt solution and fixed overnight. Thin layer slides were prepared using the Thin Prep 2000 automated slide processor (Cytyc Co, Boxborough, MA, USA). ${ }^{19} 100 \mu \mathrm{l}$ of suspension were added to $50 \mathrm{ml}$ of Preservcyt solution and placed in the automated slide processor. After dispersion, cells were automatically collected on a polycarbonate filter membrane. The thin, evenly dispersed monolayer of cells was then deposited onto the slide in a $20 \mathrm{~mm}$ circle. Residual mucus and erythrocytes were removed in the process. For each determination two slides were prepared and stained with either the Papanicolaou or May-Grünwald-Giemsa method. Differential cell counts were expressed as a percentage of lower airway cells (that is, excluding squamous epithelial cells). Differential cell counts for epithelial cells, macrophages, lymphocytes, and neutrophils were performed using Papanicolaou stained slides; differential cell counts for eosinophils were performed using May-Grünwald-Giemsa stained slides.

\section{Serum thromboxane $B_{2}\left(T_{x} B_{2}\right)$ measurement}

Compliance with ibuprofen treatment was assessed by measuring ex vivo serum $\mathrm{TxB}_{2}$ concentrations at each visit as treatment with ibuprofen suppresses production of serum $\mathrm{TxB}_{2}$ in response to endogenously formed thrombin. ${ }^{20}$ Blood drawn by a plastic syringe was immediately transferred into glass tubes and allowed to clot at $37^{\circ} \mathrm{C}$ for 30 minutes. Serum was separated by centrifugation and stored at $-20^{\circ} \mathrm{C}$ until assayed. Serum $\mathrm{TxB}_{2}$ concentrations were measured by a radioimmunoassay as described previously. ${ }^{20}$

\section{Plasma $\mathrm{PGE}_{2}$ measurement}

Compliance with rofecoxib treatment was assessed by measuring plasma $\mathrm{PGE}_{2}$ concentrations after ex vivo platelet COX-2 activation with lipopolysaccharide (LPS) and COX-1 inhibition with aspirin. ${ }^{21}$ A venous blood sample $(5 \mathrm{ml})$ was drawn and collected in a heparinised tube before (visit 2) and after treatment with rofecoxib (visit 3). One ml aliquots of whole blood samples were incubated at $37^{\circ} \mathrm{C}$ for 24 hours in tubes containing LPS $(10 \mu \mathrm{g} / \mathrm{ml})$ to activate COX-2 and a low dose of aspirin $(10 \mu \mathrm{g} / \mathrm{ml})$ to selectively suppress platelet COX-1 or tubes containing no LPS to assess basal $\mathrm{PGE}_{2}$ production derived from COX-2 (control samples). Plasma was separated by centrifugation and kept at $-30^{\circ} \mathrm{C}$ until assayed for $\mathrm{PGE}_{2}$ as described previously. ${ }^{21} \mathrm{COX}-2$ inhibition after rofecoxib was expressed as percentage of decrease in plasma $\mathrm{PGE}_{2}$ concentrations compared with pretreatment values in LPS containing samples after subtracting basal plasma $\mathrm{PGE}_{2}$ concentrations (control samples).

\section{Arterial blood gas tensions}

Arterial oxygen and carbon dioxide tensions $\left(\mathrm{PaO}_{2}, \mathrm{PaCO}_{2}\right)$ and $\mathrm{pH}$ were measured using an ABL 510 blood/gas analyser (Radiometer, Copenhagen, Denmark).

\section{Sample size}

The sample size for both studies was calculated ${ }^{22}$ considering $\mathrm{LTB}_{4}$ concentrations in EBC as the primary outcome. Sample size was estimated to be 15 subjects based on exhaled LTB $_{4}$ concentrations, after having considered a standard deviation of $20 \mathrm{pg} / \mathrm{ml}$, a drop out rate of $20 \%$, and identified the minimal difference of biological significance $(33.8 \mathrm{pg} / \mathrm{ml})$ with a power of $90 \%$ ( $\alpha$ value of $5 \%$ and $\beta$ value of $10 \%$ ). Size effect corresponds to a $33 \%$ increase in $\mathrm{LTB}_{4}$ concentrations after drug treatment.

\section{Statistical analysis}

$\mathrm{LTB}_{4}, \mathrm{PGE}_{2}$, and 8-isoprostane concentrations in EBC and cell counts in sputum were expressed as medians with interquartile range (IQR) in parentheses. Exhaled $\mathrm{LTB}_{4}, \mathrm{PGE}_{2}$ and 8 -isoprostane concentrations, cell counts in sputum within the treatment group, and comparisons before and after treatment were analysed using Friedman's repeated measures of analysis of variance. Spirometry, arterial blood gases, serum $\mathrm{TxB}_{2}$, and plasma $\mathrm{PGE}_{2}$ values followed a normal distribution and were expressed as mean (SE). Spirometric values and arterial blood gases within the treatment group and comparisons before and after treatment were analysed using repeated measures of analysis of variance with
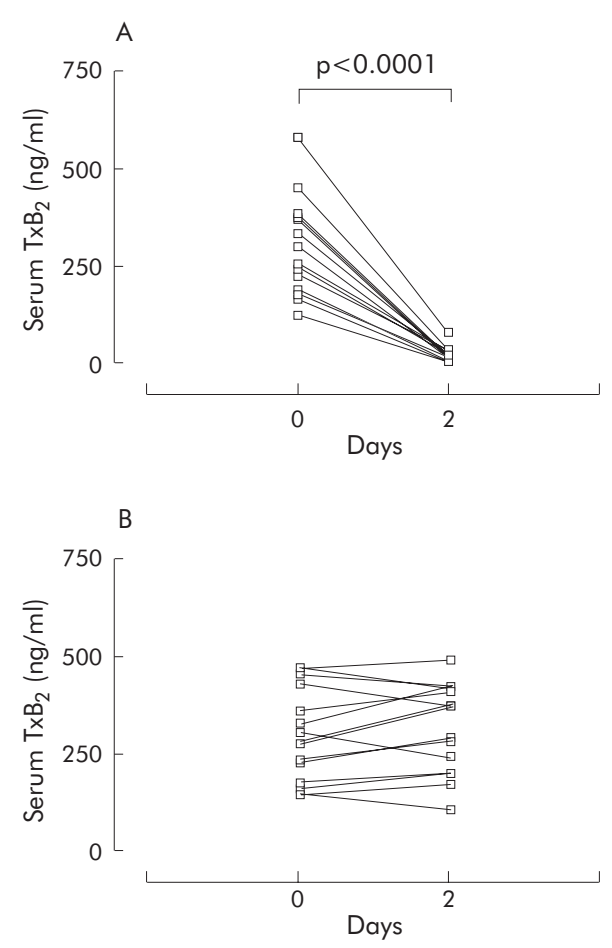

Figure 1 Serum thromboxane $B_{2}\left(T \times B_{2}\right)$ concentrations ex vivo before (day 0 ) and after treatment (day 2) with (A) oral ibuprofen $(400 \mathrm{mg}$ four times a day) or (B) matched placebo for 2 days in patients with COPD $(n=14)$. Values are expressed as means. 


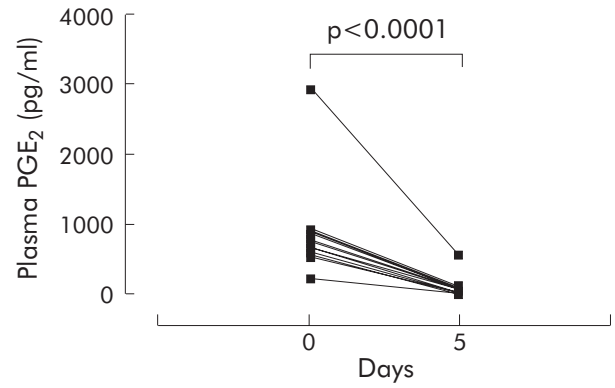

Figure 2 Plasma prostaglandin $\mathrm{E}_{2}\left(\mathrm{PGE}_{2}\right)$ concentrations after ex vivo platelet COX-2 activation with lipopolysaccharide $(10 \mu \mathrm{g} / \mathrm{ml})$ and COX1 inhibition with aspirin $(10 \mu \mathrm{g} / \mathrm{ml}$ ) before (day 0$)$ and after treatment (day 5) with oral rofecoxib ( $25 \mathrm{mg}$ once a day for 5 days) in patients with COPD $(n=16)$ Values are expressed as means.

Newman-Keuls test. For comparing plasma $\mathrm{PGE}_{2}$ and serum $\mathrm{TxB}_{2}$ values, a paired $t$ test was used. A p value of $<0.05$ was considered significant. Correlation was expressed as Spearman's correlation coefficient.

\section{RESULTS}

No amylase activity $(<22 \mathrm{U} / \mathrm{ml})$ was detected in any study sample, excluding significant salivary contamination.

Mean serum $\mathrm{TxB}_{2}$ concentrations ex vivo were reduced by 93.9\% after treatment with ibuprofen $(\mathrm{p}<0.0001$, fig $1 \mathrm{~A})$ but not after placebo $(p=0.29$, fig $1 \mathrm{~B})$. The reduction in $\mathrm{TxB}_{2}$ concentration was more than $85 \%$ in all patients, indicating compliance with treatment. Following rofecoxib treatment there was a reduction in the LPS induced increase in plasma $\mathrm{PGE}_{2}$ concentrations compared with pretreatment values $(\mathrm{p}<0.0001$, fig 2$)$. This reduction was more than $80 \%$ in all patients, indicating compliance with treatment. Treatment with ibuprofen and rofecoxib was well tolerated.
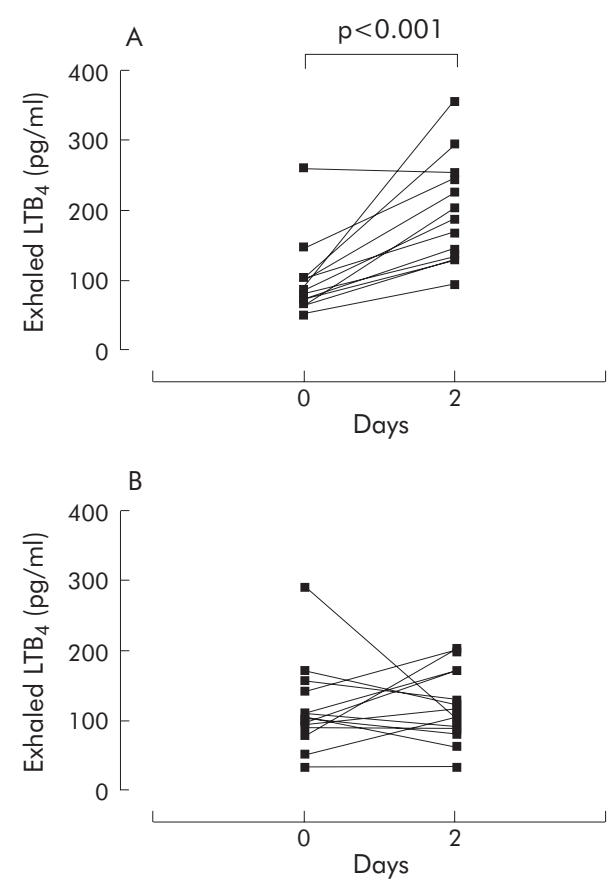

Figure 3 Leukotriene $\mathrm{B}_{4}\left(\mathrm{LTB}_{4}\right)$ concentrations in exhaled breath condensate before (day 0 ) and after treatment (day 2) with (A) oral ibuprofen ( $400 \mathrm{mg}$ four times a day) or (B) matched placebo for 2 days in patients with COPD $(n=14)$. Values are expressed as medians.
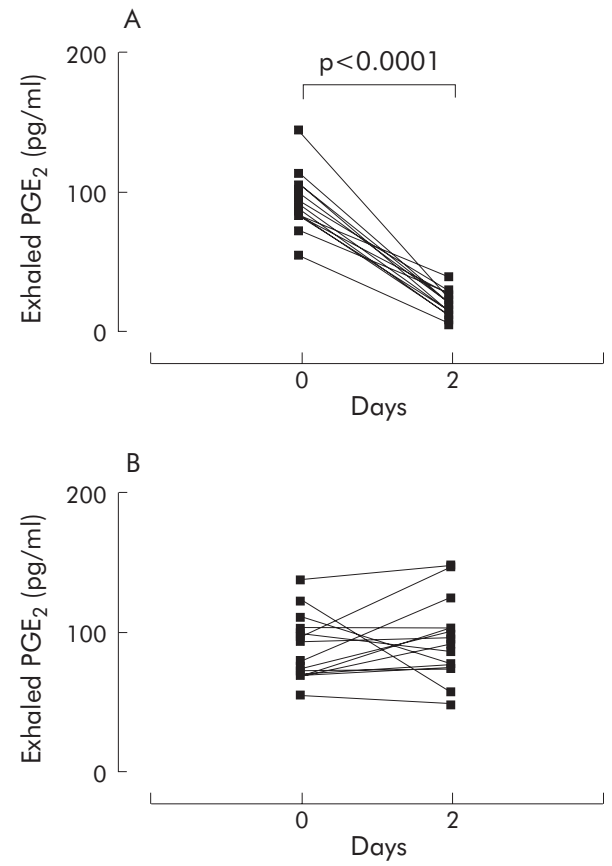

Figure 4 Prostaglandin $\mathrm{E}_{2}\left(\mathrm{PGE}_{2}\right)$ concentrations in exhaled breath condensate before (day 0 ) and after treatment (day 2 ) with $(A)$ oral ibuprofen (400 mg four times a day) or (B) matched placebo for 2 days in patients with COPD $(n=14)$. Values are expressed as medians.

\section{Exhaled breath condensate} Ibuprofen study

Exhaled $\mathrm{LTB}_{4}$ concentrations were increased after drug treatment (175.5 (128.8-231.5) pg/ml $v 84.0$ (70.0-98.5) pg/ $\mathrm{ml}), \mathrm{p}<0.001$; fig 3A) but not after placebo (104.5 (92.8$126.5) \mathrm{pg} / \mathrm{ml} v 111.0(91.0-150.5) \mathrm{pg} / \mathrm{ml}, \mathrm{p}=0.87$; fig 3B). Exhaled $\mathrm{PGE}_{2}$ concentrations were reduced after treatment with ibuprofen $(93.5 \quad(84.0-105.5) \mathrm{pg} / \mathrm{ml} \quad v \quad 22.0 \quad(15.0-$ $25.5) \mathrm{pg} / \mathrm{ml}, \mathrm{p}<0.0001$; fig $4 \mathrm{~A}$ ) but not after placebo (88.0 (72.5-103.0) pg/ml $v 95.5 \quad(72.5-104.0) \mathrm{pg} / \mathrm{ml}, \quad \mathrm{p}=0.49$; fig 4B). Ibuprofen did not affect exhaled 8-isoprostane concentrations (ibuprofen: 47.9 (40.5-51.9) pg/ml pre-treatment $v 42.2(34.9-60.0) \mathrm{pg} / \mathrm{ml}$ post-treatment, $\mathrm{p}=0.64$, fig 5A; placebo: $38.3(31.0-43.8) \mathrm{pg} / \mathrm{ml}$ pre-treatment $v 40.6$ (25.1-45.2) $\mathrm{pg} / \mathrm{ml}$ post-treatment, $\mathrm{p}=0.87$, fig 5B).

There was no correlation between exhaled eicosanoids and spirometric values. The intraclass correlation coefficient was 0.75 for $\mathrm{LTB}_{4}(\mathrm{p}<0.001), 0.87$ for $\mathrm{PGE}_{2}(\mathrm{p}<0.0001)$ and 0.79 for 8 -isoprostane $(\mathrm{p}<0.001)$.

\section{Rofecoxib study}

Rofecoxib had no effect on median exhaled $\mathrm{LTB}_{4}$ (pretreatment $89.4(81.8-116.4) \mathrm{pg} / \mathrm{ml} \quad v$ post-treatment 83.8 (64.4-105.6) pg/ml, p=0.53; fig 6A), $\mathrm{PGE}_{2}$ (pre-treatment $89.3 \quad(75.5-100.5) \mathrm{pg} / \mathrm{ml} \quad v$ post-treatment $91.5 \quad(85.5-$ 102.8) $\mathrm{pg} / \mathrm{ml}, \mathrm{p}=0.23$; fig $6 \mathrm{~B}$ ), or 8 -isoprostane concentrations (pre-treatment $39.5(33.0-46.5) \mathrm{pg} / \mathrm{ml} v$ post-treatment 39.5 (34.8-43.5) pg/ml, $\mathrm{p}=0.93$; fig 6C).

There was a negative correlation between 8 -isoprostane concentrations in $\mathrm{EBC}$ and $\mathrm{PaO}_{2}$ values at baseline $(r=-0.67, \mathrm{p}=0.045, \mathrm{n}=16)$ (fig $\mathrm{S} 3$ available online at http://www.thoraxjnl.com/supplemental). There was no correlation between exhaled eicosanoids and spirometric values. There was no correlation between exhaled markers and either absolute or relative cell counts in sputum. The intraclass correlation coefficient was $0.67(\mathrm{p}<0.001)$ for $\mathrm{LTB}_{4}, 0.82$ $(\mathrm{p}<0.0001)$ for $\mathrm{PGE}_{2}$, and $0.75(\mathrm{p}<0.0001)$ for 8-isoprostane. 

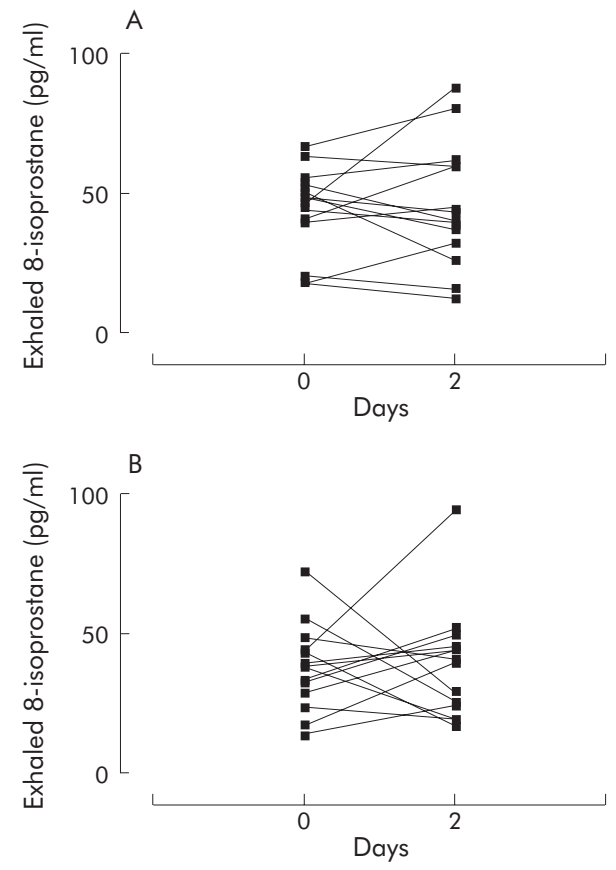

Figure 5 8-Isoprostane concentrations in exhaled breath condensate before (day 0 ) and after treatment (day 2) with (A) oral ibuprofen (400 mg four times a day) or (B) matched placebo for 2 days in patients with COPD $(n=14)$. Values are expressed as medians.

\section{Pulmonary function tests Ibuprofen study}

Treatment with ibuprofen or placebo had no effect on FEV $_{1}$ $(p=0.61)$, FVC $(p=0.26)$, and $\mathrm{FEV}_{\mathrm{l}} / \mathrm{FVC}$ ratio $(\mathrm{p}=0.99)$ (see tables $\mathrm{S} 1$ and $\mathrm{S} 2$ available online at http://www. thoraxjnl.com/supplemental).

\section{Rofecoxib study}

Rofecoxib had no effect on $\mathrm{FEV}_{1}(\mathrm{p}=0.45)$, FVC $(\mathrm{p}=0.52)$, and $\mathrm{FEV}_{\mathrm{l}} / \mathrm{FVC}$ ratio $(\mathrm{p}=0.82)$ (see table $\mathrm{S} 3$ available online at http://www.thoraxjnl.com/supplemental).

\section{Sputum induction \\ Rofecoxib study}

Three samples from one patient had more than 50\% squamous cell contamination and were excluded from analysis. Differential or absolute counts of any cell type at baseline and after the run-in period were similar (see table S4 available online at http://www.thoraxjnl.com/supplemental).

Rofecoxib had no effect on absolute (total cells, $p=0.55$; macrophages, $\mathrm{p}=0.77$; neutrophils, $\mathrm{p}=0.77$; lymphocytes, $\mathrm{p}=0.42$; eosinophils, $\mathrm{p}=0.77$ ) or differential sputum cell counts (squamous cells, $p=0.77$; macrophages, $p=0.31$; neutrophils, $\mathrm{p}=0.59$; lymphocytes, $\mathrm{p}=0.53$; eosinophils, $\mathrm{p}=0.69$ ) (see table S4 available online at http://www.thoraxjnl.com/supplemental).

\section{Arterial blood gases \\ Rofecoxib study}

In 10 out of 16 patients arterial blood gas measurements were performed on visits 1, 2, and 3. Six patients who participated in the study refused to have a second arterial blood gas measurement. In the 10 patients who had three arterial blood gas measurements the mean $\mathrm{PaO}_{2}$ was increased by $4.2 \mathrm{~mm} \mathrm{Hg}$ after rofecoxib, although statistical significance was not reached (pre-treatment $73.3 \quad$ (1.8) $\mathrm{mm} \mathrm{Hg}$; post-treatment 77.5 (3.3) $\mathrm{mm} \mathrm{Hg}, \mathrm{p}=0.42$ ) (see fig S4A available online at http://www.thoraxjnl.com/supplemental).


Figure 6 (A) $\mathrm{LTB}_{4},(\mathrm{~B}) \mathrm{PGE}_{2}$, and (C) 8-isoprostane concentrations in exhaled breath condensate in patients with COPD at baseline (day-14), before (day 0$)$, and after treatment with oral rofecoxib $25 \mathrm{mg}$ once a day for 5 days (day 5$)$ in patients with COPD $(n=16)$. Values are expressed as medians.

Rofecoxib had no effect on $\mathrm{PaCO}_{2}$ or $\mathrm{pH}$ values (see fig $\mathrm{S} 4 \mathrm{~B}$ and $\mathrm{C}$ in online supplement).

\section{DISCUSSION}

We have investigated the effects of COX inhibition on exhaled $\mathrm{LTB}_{4}, \mathrm{PGE}_{2}$, and 8-isoprostane concentrations in patients with COPD. All patients complied with treatment as reflected by a reduction in ex vivo serum $\mathrm{TxB}_{2}$ concentrations after ibuprofen of more than $85 \%$ and inhibition of LPS induced increase in plasma $\mathrm{PGE}_{2}$ values after rofecoxib of more than $80 \%$ in each patient. The specificity of the enzyme immunoassay for $\mathrm{LTB}_{4}$ and the radioimmunoassays for 8isoprostane and $\mathrm{PGE}_{2}$ has been shown previously by RPHPLC. ${ }^{16}{ }^{17}$ Day to day repeatability for exhaled eicosanoid measurements is acceptable, as indicated by their intraclass correlation coefficients consistent with previous findings. ${ }^{23}$ In a randomised, double blind, placebo controlled, crossover study, ibuprofen, a non-selective COX inhibitor, given orally at a dose of $1600 \mathrm{mg} /$ day for 2 days, increased $\mathrm{LTB}_{4}$ concentrations and decreased $\mathrm{PGE}_{2}$ concentrations in $\mathrm{EBC}$ in patients with stable COPD. By contrast, in a different study of open label design, oral administration of rofecoxib 
( $25 \mathrm{mg} /$ day for 5 days), a selective COX-2 inhibitor, had no effect on these eicosanoids. Other authors have reported increased $\mathrm{LTB}_{4}$ concentrations in bronchoalveolar lavage (BAL) fluid from allergic COX-1 deficient mice compared with allergic wild type and COX-2 deficient mice. ${ }^{24}$ Taken together, these data indicate that COX-1 inhibition can divert arachidonic acid to other metabolic products (such as leukotrienes) under conditions of increased lung inflammation. $\mathrm{LTB}_{4}$ is a potent chemoattractant for neutrophils which have an important pathophysiological role in COPD. ${ }^{25}$ Increased exhaled $\mathrm{LTB}_{4}$ concentrations in patients with COPD treated with ibuprofen might indicate that airway inflammation in these patients is increased after nonselective COX inhibition. These effects are not observed after rofecoxib, which indicates that selective COX-2 inhibitors might be more tolerated than other NSAIDs in patients with COPD. However, the lack of administration of a non-selective and a selective COX-2 inhibitor to the same group of patients and the open label uncontrolled design of the rofecoxib study limit the strength of these findings and preclude definitive conclusions.

In the ibuprofen study six of the 14 patients were on inhaled corticosteroids, whereas all the rofecoxib study group patients were steroid naïve. A previous observational study showed that inhaled steroids had a limited, if any, effect on exhaled eicosanoids in patients with COPD. ${ }^{8}$ However, studies are needed to address formally the influence of steroid treatment on exhaled eicosanoids in patients treated with COX inhibitors. As ibuprofen decreases exhaled $\mathrm{PGE}_{2}$ concentrations in patients with COPD while rofecoxib does not, the present study indicates that COX-1 is primarily responsible for exhaled $\mathrm{PGE}_{2}$ production. Similar $\mathrm{PGE}_{2}$ levels in BAL fluid were reported in allergic wild type and COX-2 deficient mice. ${ }^{24}$ By contrast, prostaglandin synthesis in allergic guinea pig lungs in vitro has been reported to be significantly dependent on COX-2. ${ }^{26}$ This discrepancy may partially be explained by in vitro/in vivo differences in expression and regulation of COX isoforms ${ }^{24}$ and/or differences in the inflammatory process (allergen challenge $v$ COPD). Data on the effect of COX inhibitors in the present studies should be interpreted cautiously as COPD severity was different in the rofecoxib and ibuprofen study group patients (moderate and severe, respectively). Further studies are required to clarify whether the effect of COX inhibitors on exhaled eicosanoids in COPD is affected by disease severity, whether the difference between the action of the two drugs is related to COX independent mechanisms, and the long term effect of COX inhibitors on exhaled eicosanoids in patients with COPD. Findings on the functional consequences of COX inhibition on airway inflammation are controversial, ${ }^{26}{ }^{27}$ possibly due to the fact that COX inhibitors abrogate the synthesis of both pro- and anti-inflammatory prostaglandins $\left(\mathrm{PGD}_{2} v \mathrm{PGE}_{2}\right){ }^{28}$ The lack of effect of ibuprofen and rofecoxib on exhaled 8-isoprostane concentrations indicates that this compound is primarily formed independently of the COX pathway. ${ }^{\text {. }}$

The values of exhaled eicosanoids in our study are given per ml EBC, as in most of the published studies on exhaled biomarkers. This approach may have limitations since many factors are likely to affect differentially the volume of EBC and the concentrations of various compounds in it, including differences in EBC collection, sample storage, analytical techniques, and disease severity. ${ }^{11}$ As pointed out by Effros and co-workers, part of the variation in the concentrations of non-volatile compounds in EBC can be related to differences in the dilution of respiratory droplets by water vapour. ${ }^{29}$ The lack of correlation between structurally related compounds such as 8 -isoprostane and $\mathrm{PGE}_{2}$ observed in this study and the selective increase of leukotrienes $\left(\mathrm{LTB}_{4} v \mathrm{LTE}_{4}\right)$ in the single subject previously reported ${ }^{8}$ do not seem to support this evidence. However, reference indicators, such as the measurement of conductivity as proposed by Effros and coworkers, ${ }^{30}$ should be used in future studies aimed at quantifying exhaled eicosanoids. At present, because of the lack of a standardised procedure for EBC collection and validated analytical methods, comparisons of data obtained in different laboratories are difficult. ${ }^{11}$ The fact that eicosanoid concentrations in EBC are not more diluted than those observed in BAL fluid might indicate that these compounds are somewhat volatile and reach the $\mathrm{EBC}$ in the gas phase. However, recent data indicate that $\mathrm{LTB}_{4}$ is not volatile ( $\mathrm{P}$ Montuschi, unpublished data). The physical and chemical properties of eicosanoids in EBC are largely unknown and require further research. EBC analysis is currently more reliable for measuring relative values than for determining absolute levels of inflammatory mediators.

No changes were seen in lung function tests or sputum cell counts after short term treatment with oral ibuprofen or rofecoxib at therapeutic doses. Similarly, 1 week of treatment with oral celecoxib (200 mg twice daily), another selective COX-2 inhibitor, did not affect bronchial responsiveness in asthmatic patients. ${ }^{31}$ However, possible effects on lung function and/or sputum cell counts after longer treatment with COX inhibitors cannot be ruled out. The mean $\mathrm{PaO}_{2}$ was increased by $4.2 \mathrm{~mm} \mathrm{Hg}$ after rofecoxib, although statistical significance was not reached $(p=0.42)$. The biological significance of these findings is currently unknown, as is the effect on $\mathrm{PaO}_{2}$ of long term treatment with selective COX2 inhibitors.

In conclusion, short term non-selective $\mathrm{COX}$ inhibition increases $\mathrm{LTB}_{4}$ and reduces $\mathrm{PGE}_{2}$ concentrations in EBC in patients with COPD, whereas selective COX-2 inhibition does not seem to have these effects. These findings indicate that exhaled $\mathrm{PGE}_{2}$ is primarily derived from COX-1 activity and that COX-1 inhibition may redirect arachidonic acid metabolism towards the 5-lipoxygenase pathway. However, controlled studies with non-selective and selective COX inhibitors in the same group of patients with COPD are required to draw definitive conclusions.

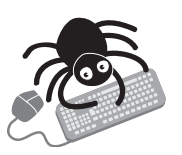

Figures S1-S4 and tables S1-S4 are available in the online supplement at http://www.thoraxjnl.com/supplemental

\section{Authors' affiliations}

P Montuschi, Department of Pharmacology, School of Medicine, Catholic University of the Sacred Heart, Rome, Italy

F Macagno, S Valente, G Ciappi, Department of Internal Medicine, School of Medicine, Catholic University of the Sacred Heart, Rome, Italy P Parente, L Lauriola, Department of Pathology, School of Medicine, Catholic University of the Sacred Heart, Rome, Italy

S A Kharitonov, P J Barnes, Department of Thoracic Medicine, Imperial College, School of Medicine, National Heart and Lung Institute, London, UK

G Ciabattoni, Department of Drug Sciences, School of Pharmacy, University "G D'Annunzio", Italy

The ibuprofen study was funded by Imperial College, School of Medicine at the National Heart and Lung Institute, London, UK. The rofecoxib study was funded by Merck, Sharp \& Dohme.

PM, FM, PP, SV, LL, GC, PJB, and GC have no competing interests. They have no financial and/or personal relationships with other people or organisations that could inappropriately influence this work.

This work was performed at Imperial College, School of Medicine, National Heart and Lung Institute, London, UK and at the Catholic University of the Sacred Heart, Rome, Italy. 


\section{REFERENCES}

1 Hill AT, Bayley D, Stockley RA. The interrelationship of sputum inflammatory markers in patients with chronic bronchitis. Am J Respir Crit Care Med 1999; 160:893-8

2 Gompertz S, O'Brien C, Bayley DL, et al. Changes in bronchial inflammation during acute exacerbations of chronic bronchitis. Eur Respir J 2001:17:1112-9.

3 Pavord ID, Tattersfield AE. Bronchoprotective role for endogenous prostaglandin $\mathrm{E}_{2}$. Lancet 1995;345:436-8.

4 Gauvreau GM, Watson RM, O'Byrne PM. Protective effects of inhaled PGE on allergen-induced airway responses and airway inflammation. Am J Respir Crit Care Med 1999;159:31-6.

5 Kharitonov SA, Sapienza MA, Barnes PJ, et al. Prostaglandin $E_{2}$ and $F_{2 \alpha}$ reduce exhaled nitric oxide in normal and asthmatic subjects irrespective of airway caliber changes. Am J Respir Crit Care Med 1998;158:1374-8.

6 Morrow JD, Hill KE, Burk RF, et al. A series of prostaglandin F2-like compounds are produced in vivo in humans by a non-cyclooxygenase, freeradical-catalyzed mechanism. Proc Natl Acad Sci USA 1990;87:9383-7.

7 Montuschi P, Barnes PJ, Roberts $U$ II. Isoprostanes: markers and mediators of oxidative stress. FASEB J 2004;18:1791-800.

8 Montuschi P, Kharitonov SA, Ciabattoni G, et al. Exhaled leukotrienes and prostaglandins in COPD. Thorax 2003;58:585-8.

9 Montuschi P, Collins JV, Ciabattoni G, et al. Exhaled 8-isoprostane as an in vivo biomarker of lung oxidative stress in patients with COPD and healthy smokers. Am J Respir Crit Care Med 2000;162:1175-7.

10 Mutlu GM, Garey KW, Robbins RA, et al. Collection and analysis of exhaled breath condensate in humans. Am J Respir Crit Care Med 2001;164:731-7.

11 Montuschi P. Indirect monitoring of lung inflammation. Nat Rev Drug Discov 2002; 1:238-42.

12 Montuschi P, Barnes PJ. Analysis of exhaled breath condensate for monitoring airway inflammation. Trends Pharmacol Sci 2002;23:232-7.

13 Montuschi P, Ciabattoni G, Kharitonov SA, et al. Non selective cyclooxygenase inhibition decreases exhaled prostaglandin $\mathrm{E}_{2}$ in patients with chronic obstructive pulmonary disease. Am J Respir Crit Care Med 2001; 163:A908.

14 Montuschi P, Barnes PJ. Exhaled leukotrienes and prostaglandins in asthma. $J$ Allergy Clin Immunol 2002; 109:615-20.

15 National Heart, Lung, and Blood Institute. Global initiative for chronic obstructive lung disease, NHLBI/WHO Workshop Report. Publication No 2701. Bethesda, MD: National Institute of Health, 2001 (updated 2003).

16 Montuschi P, Ragazzoni E, Valente $S$, et al. Validation of leukotriene $B_{4}$ measurements in exhaled breath condensate. Inflamm Res 2003;52:69-73.
17 Montuschi P, Ragazzoni E, Valente S, et al. Validation of 8-isoprostane and prostaglandin $\mathrm{E}_{2}$ measurements in exhaled breath condensate. Inflamm Res 2003;52:502-6.

18 Nightingale JA, Rogers DF, Hart LA, et al. Effect of inhaled endotoxin on induced sputum in normal atopic and atopic asthmatic subjects. Thorax 1998;53:563-71.

19 Zimmerman RL, Montone KT, Fogt F, et al. Ultra fast identification of Aspergillus species in pulmonary cytology specimens by in situ hybridisation. Int J Mol Med 2000;5:427-9.

20 Patrono $C$, Ciabattoni G, Pinca $E$, et al. Low dose aspirin and inhibition of thromboxane $\mathrm{B}_{2}$ production in healthy subjects. Thromb Res 1980;17:317-27.

21 Patrignani P, Santini G, Panara MR, et al. Induction of prostaglandin endoperoxide synthase- 2 in human monocytes associated with cyclooxygenase-dependent F2-isoprostane formation. Br J Pharmacol 1996; 118:1285-93.

22 Florey CV. Sample size for beginners. BMJ 1993;306:1181-4

23 Montuschi P, Varone F, Valente S, et al. Methodological aspects of exhaled prostanoid measurements. Eur Respir J 2003;22(Suppl 45):18s.

24 Gavett SH, Madison SL, Chulada PC, et al. Allergic responses are increased in prostaglandin $\mathrm{H}$ synthase-deficient mice. J Clin Invest 1999; 104:721-32.

25 Hogg JC. Pathophysiology of airflow limitation in chronic obstructive pulmonary disease. Lancet 2004;364:709-21.

26 Oguma T, Asano K, Shiomi T, et al. Cyclooxygenase-2 expression during allergic inflammation in guinea-pig lungs. Am J Respir Crit Care Med 2002; 165:382-6.

27 Peebles RS Jr, Hashimoto K, Morrow JD, et al. Selective cyclooxygenase-1 and -2 inhibitors each increase allergic inflammation and airway hyperresponsiveness. Am J Respir Crit Care Med 2002;165:1154-60.

28 Peters-Golden M. Open mind, open airways. Broadening the paradigm of prostaglandins and allergic airway inflammation. Am J Respir Crit Care Med 2002; 165:1035-6.

29 Effros RM, Hoagland KW, Bosbous $M$, et al. Dilution of respiratory solutes in exhaled condensates. Am J Respir Crit Care Med 2002;165:663-9.

30 Effros RM, Biller J, Foss B, et al. A simple method for estimating respiratory solute dilution in exhaled breath condensate. Am J Respir Crit Care Med 2003; 168:1500-5.

31 Dicpinigaitis PV. Effect of the cyclooxygenase-2 inhibitor celecoxib on bronchial responsiveness and cough reflex sensitivity in asthmatics. Pulm Pharmacol Ther 2001; 14:93-7.

\section{LUNG ALERT}

Rapid disease progression is an important cause of death in IPF

$\Delta$ Martinez FJ, Safrin S, Weycker D, et al for the IPF Study Group. The clinical course of patients with idiopathic pulmonary fibrosis. Ann Intern Med 2005;142:963-8 he authors examined data generated from the placebo arm of a large multicentre double blind trial of interferon- $\gamma \mathrm{lb}$ in patients with mild to moderate idiopathic pulmonary fibrosis (IPF), collected over a median period of 76 weeks at 12 weekly intervals. IPF was diagnosed according to the ATS criteria, by surgical lung biopsy or established HRCT criteria in 168 patients (mean age 64 years, 66\% male, 86\% white, $91 \%$ never or exsmokers). At entry most patients (82\%) were receiving oral corticosteroids in a dose of less than $15 \mathrm{mg}$ daily, the mean duration since diagnosis was over 1 year, and the mean (SD) carbon monoxide transfer factor (TLCO) was 36.8 (10.6)\%. Patients who survived to week 72 $(78.6 \%)$ had minimal deterioration in physiology and dyspnoea (FVC, TLCO, A-a gradient, transitional dyspnoea index). Thirty six patients (21.4\%) died during the observation period. In those who died of an IPF related death (32/36), nearly 50\% died acutely $(<4$ weeks). Progression of IPF and pneumonia were the most common causes $(63 \%$ and $13 \%$, respectively). Patients who died had a progressive decline in measures of physiology and dyspnoea throughout the observation period. More than one third of patients were admitted to hospital, often frequently ( 1.67 admissions/patient), $23 \%$ for a respiratory disorder with a mean length of stay of 14.3 days.

This study provides novel insights into the natural history of IPF. In particular, a large percentage of deaths had an acute onset, suggesting that accelerated IPF may be more common than was once perceived. Hospitalisation occurred commonly and frequently. A substantial proportion of patients had a minimal decline in conventional measures of lung function and dyspnoea, highlighting disease heterogeneity and posing challenges for measuring efficacy of new pharmaceutical compounds. Further prospective studies are required to elaborate on these findings.

S H Siddiqui

SPR/Clinical Research Fellow in Respiratory Medicine, Glenfield Hospital, Leicester, UK Salman95@yahoo.com 